https://doi.org/10.46344/JBINO.2021.v010i01.25

\title{
MECHANISMS OF URANIUM AND LIGHT RARE EARTH ELEMENTS REMOVAL USING SARGASSUM DETOFIULUM AS A BIOSORBENT
}

\author{
Nora Sh. Gad \\ Nuclear Materials Authority of Egypt (NMA), P.O. Box 305 Maadi, Cairo \\ Email: norashenouda@yahoo.com
}

\begin{abstract}
The biosorbent material Sargassum detofiulum to recover uranium and light Rare earth metals (L. REEs) from samples of trachyte sills of Nasb El Atshan area, Central Eastern Desert, Egypt, one sample has a promising result for biosorption with studying the mechanisms such as complexation, ion exchange and precipitation. In order to understand how uranium and L. REEs binds to the biosorbent material Sargassum detofiulum, it is essential to identify the functional groups responsible for this metal binding. Sargassum detofiulum has proved to be very promising, for it's economically, profitability, availability, ease of operation, and high efficiency.
\end{abstract}

Key word: Sargassum detofiulum, biosorption, mechanism, uranium, light Rare earth, trachyte sills. 


\section{INTRODUCTION}

Rare earth elements are a group of chemical elements which occur together in the periodic table. The use of rare earth elements has been grown almost as fast as cell phones; many rechargeable batteries are made of rare earth compounds. Demand for the batteries is being driven by demand for portable electronic devices such as cell phones, readers, portable computers, and cameras, as the trachyte sills of Nasb El Atshan area contain high quantity of light rare earth, they are chosen in this research and Sargassum detofiulum is used as a biosorbent for this L REEs after (Senthilkumaar et al., 2000\& Abou Zeid et al., 2009). The process features a high selectivity and cost-effectiveness for low metal concentrations, compared to the common methods, (Azzoni et al., 1995 \& Gadd 2001). Using biomass for adsorption and removal of REES can have revenue for industries presently wasting the biomass. Moreover, the biomass can grow using simple fermentation methods and inexpensive growth media. (Kulbat et al., 2003).

The fate of residual bio-sorbent in fact remains relatively unanswered. Different techniques such as precipitation and electro-winning have been applied to recover metals from concentrated solution. Environmental factors that may influence the metal-binding capacity of microorganisms include temperature, type; concentration; oxidation state of metal, composition and $\mathrm{pH}$, type of microorganisms; mechanism of metal removal, both cationic; anionic, simultaneous presence of inorganic ; organic components; presence of

dissolved; volatile species, colloids, emulsions, and particles (Zouboulis., et al 1996, Diniz ., et al 2008 \& Kato., et al 2003 ).

The aim of this paper is to clarify the mechanism involved in biosorbtion of uranium and L. REEs using (S. detofiulum) as a biosorbent. Recent studies have focused our understanding of the mechanisms followed in this research.

\section{2-Material and method}

\subsection{Algal collection and processing}

S. detofiulum was collected from Red Sea on the coast of Hurghada, Egypt, transferred to laboratory in labelled polyethylene bags. The samples were washed several times with de-ionized water to remove dirt, and/or other impurities present in the raw materials. They were air dried for 10 days, then grinded and sieved at the pore size of 0.5 to $1 \mathrm{~mm}$.

\subsection{Characterization of the algal- biosorbent materials}

Infra-red (IR) spectrum of model Naxux 670 was applied in a spectrum ranges of $400-4000 \mathrm{~cm}^{-1}$ for the sample to identify the functional groups in the Central National Research (CNR) and the morphological characteristics of the algal biomasses surface and the pore and particles fractions were examined under environmental scanning electron microscope (ESEM), field emission gun 
(FIG) in the Central National Research (CNR).

\subsection{Samples location}

Samples were collected from Nasb El- Atshan area, Central Eastern Desert, Egypt. Lay in latitudes $25^{\circ} 53^{\circ}$ and $25^{\circ} 51^{\prime}$ $\mathrm{N}$ and longitudes $34^{\circ} 05^{\circ}$ and $34^{\circ} 07^{\circ} \mathrm{E}$. All rocks are dissected and traversed by numerous post-orogenic trachyte dykes and sills, selected samples of trachyte sills from Nasb El- Atshan area, was grinded to a size of 100 mesh and subjected to different analysis .

\subsection{Adsorption experiments}

In order to investigate the ability of the S. detofiulum biosorbent material to recover (uranium and L. REEs) from the aqueous solutions of selected samples of trachyte sills from Nasb El-Atshan area, batch experiments were conducted by contacting (uranium and L. REEs) solutions with the adsorbent (1 G/L).

The flasks were placed on a shaker with constant shaking for 100 rpm, and then incubated at $30{ }^{\circ} \mathrm{C}$ for 5 days. The algal biomass was washed several times as outlined in the work of (Kato ., et al 2003 \& Hasan., et al 2003).

Then

Environmental

examined

using microscope (ESEM) and chemically to determine L. REEs concentration from the biomass. The samples were examined under Infrared Spectroscopy (IR) using the model Naxux 670 FTIR, in (CNR), Environmental scanning electron microscope (ESEM), field emission gun (FIG) in the Central National Research (CNR) and L. REEs measured by (Inductive coupled plasma spectroscopy) ICP in Nuclear Materials Authority (NMA).

\subsection{Adsorption isotherms}

To determine the equation between biosorbent material ( $S$. detofiulum) and the adsorbate (selected samples of trachyte sills from Nasb ElAtshan area), by using Langmuir model. The amount of adsorbed ( $U$ and L. REEs) $(\mathrm{mg} / \mathrm{g})$ at equilibrium (qe) was calculated from the mass balance expression given by (Hanan H.Omer 2008):

$$
\mathbf{q e}=\frac{(\mathrm{Co}-\mathrm{Ce})}{\mathrm{m}} \mathbf{v}
$$

Where, Co and $\mathrm{Ce}$ are the liquid phase concentrations (mg/l) of (uranium and L.REEs) at an initial and at equilibrium, respectively. $V$ for volume $(L)$ and $m$ is the biosorbent material ( $S$. detofiulum) mass (g).

\section{3-Result and Discussion}

Many techniques were used to determine the characterization of the biosorbent material (S. detofiulum) and the nature of the biomasses (samples of trachyte)

\subsection{Chemical analysis}

Five samples of trachyte sills from Nasb El-Atshan area were chosen to determine the effect of $S$. detofiulum biosorption to $U$ and $L$. REEs contents, Table (1). Uranium recorded that sample 1 and 2 have highly absorption capacity about $(96 \%$ to $92 \%)$ and sample 5 indicates the absorption capacity by $S$. detofiulum about $89 \%$ of uranium content, on the other hand sample 3 and 
4 show the absorption capacity about (75\% and $77 \%$ ).

By studying the absorption of L.REEs from the trachyte sills of Nasb El-Atshan area as shown in table (1) in the five samples Lanthanum (La) before using $S$. detofiulum in the samples was 1 $124.8,111.3,89,54$ and 22 ppm ) after absorption it became $(4.2,11.1,24.9$ ,12.4 and 2.42 ppm ) respectively while cerium (Ce) content was $(273.8,230.2$, 150,87 and $11 \mathrm{ppm}$ ) after biosorption it became $(11,18.4,37.51,16.4$ and 2.75 ppm ) respectively.

According to the carried analysis for Prascodymium (Pr) from the experiments data results before using was (30, 23,13, 7 and 2 ppm) after treating with $S$. detofiulum the result data became $(1.2,2.1,3,2.1$ and $0.6 \mathrm{ppm})$ respectively, from the absorption

Neodymium (Nd) result was (108.9, 99, 65, 32 and 17 ppm) after treatment they became $(4.4,10,3.9,7.7$ and 5.44 ppm ) respectively.

Samarium ( $\mathrm{Sm}$ ) date was (18.2, 15 , 8,3 and $1 \mathrm{ppm}$ ) after absorption it become $(0.8,1.2,2.4,1.05$ and 0.05 ppm ) respectively, from the analysis of ICPMS Europium (EU) date was (2.22, $1.8,0.8,0.6$ and 0.1 ppm ) S. detofiulum capacity for biosorption for (EU) give ( $0.1,0.3,0.29,0.24$ and $0.05 \mathrm{ppm}$ ) respectively Finally Gadolinium (Gd) data was (15.2, 10.5, 9.1, 5.4 and 1.9 ppm ) after absorption it became (0.6, 1.1, 2.7, 1.86 and 0.7 ppm ) respectively by calculating the percentage of biosorption to L.REEs by $S$. detofiulum on the five samples of trachyte sills in Nasb El-Atshan area we can conclude that sample 1 is the most perfect sample for studying the mechanism of using $S$. detofiulum as a biosorpant.

Table (1): Chemical analysis of U and L. REEs (ppm) for trachytic sills

$\mathrm{m}$

\begin{tabular}{|c|c|c|c|c|c|c|c|c|c|c|c|c|c|c|c|c|}
\hline No. & $\mathbf{U}$ & $\mathbf{L a}$ & $\mathrm{Ce}$ & Pr & Nd & Sm & $\mathbf{E u}$ & Gd & $\mathbf{U}$ & La & $\mathrm{Ce}$ & Pr & Nd & Sm & $\mathbf{E u}$ & Gd \\
\hline & \multicolumn{8}{|c|}{$\begin{array}{l}\text { Before } \\
\text { (ppm) }\end{array}$} & \multicolumn{8}{|c|}{$\begin{array}{l}\text { After } \\
(\mathbf{p p m})\end{array}$} \\
\hline 1 & 2300 & 124.8 & 237.8 & 30 & 108.9 & 18.2 & 2.22 & 15.2 & 90 & 4.2 & 11 & 1.2 & 4.4 & 0.8 & 0.1 & 0.6 \\
\hline 2 & 1800 & 111.1 & 230.2 & 23 & 99 & 15 & 1.8 & 10.5 & 235 & 11.1 & 18.4 & 2.1 & 10 & 1.2 & 0.3 & 1.1 \\
\hline 3 & 300 & 89 & 150 & 13 & 65 & 8 & 0.8 & 9.1 & 75 & 24.9 & 37.5 & 3 & 3.9 & 2.4 & 0.29 & 2.7 \\
\hline 4 & 130 & 54 & 87 & 7 & 32 & 3 & 0.6 & 5.4 & 30 & 12.4 & 16.4 & 2.1 & 7.7 & 1.05 & 0.24 & 1.86 \\
\hline 5 & 90 & 22 & 11 & 2 & 17 & 0.1 & 0.1 & 1.9 & 10 & 2.42 & 2.75 & 0.6 & 5.44 & 0.05 & 0.05 & 0.7 \\
\hline
\end{tabular}

\section{Infra-Red (IR)}

IR analysis used to determine the characterization of the biosorbent material (S. detofiulum) with the adsorbate (selected samples of trachyte sills from Nasb El- Atshan area (see Figs 1- 
5) gave the characteristic wavelength for sample No.1. Show the appearance of $\mathrm{OH}, \mathrm{CH}$ aliphatic, coupling amide and C$\mathrm{O}-\mathrm{C}$ after treatment $\mathrm{N}-\mathrm{H}$ appeared as shown in figures (1) while sample No.2. Treated with $S$. detofiulum was mention with high amount of $U$ show the presence of $\mathrm{N}-\mathrm{H}$, coupling amide and $\mathrm{C}-\mathrm{O}-\mathrm{C}$ after treatment $\mathrm{N}-\mathrm{H}$ and coupling amide demise with the appearance of $\mathrm{OH}$, $\mathrm{C}=\mathrm{C}, \mathrm{CO}$ amide and $\mathrm{SO}_{2}$ (see Fig 2).

Sample No. 3. Treated with Sargassum show $\mathrm{OH}$, coupling amide, $\mathrm{SO}_{2}$ and $\mathrm{C}-\mathrm{O}-\mathrm{C}$ after treatment coupling amide and $\mathrm{SO}_{2}$ receding from view with the appearance of $\mathrm{N}-\mathrm{H}, \mathrm{CH}$ aliphatic, (alkynes, nitriles with $\mathrm{CN}$ triple bond), $\mathrm{C}=\mathrm{C}$ and $\mathrm{CO}$ amide (see Fig 3)

Sample No. 4. Functional group before treatment with $S$. detofiulum are
$\mathrm{OH}, \mathrm{N}-\mathrm{H}, \mathrm{C}=\mathrm{C}$ and $\mathrm{C}-\mathrm{O}-\mathrm{C}$ after treatment $\mathrm{N}-\mathrm{H}, \mathrm{C}=\mathrm{C}$ receding from view with the appearance of $\mathrm{CO}$ amide (see Fig 4). Finally, sample No. 5. Show the appearance of $\mathrm{N}-\mathrm{H}, \mathrm{CH}$ aliphatic, (alkynes, nitriles with $\mathrm{CN}$ triple bond), $\mathrm{CO}$ amide, $\mathrm{SO}_{2}$ and $\mathrm{C}-\mathrm{O}-\mathrm{C}$ after treatment $\mathrm{N}$ $\mathrm{H}, \mathrm{CO}$ amide, $\mathrm{SO}_{2}$ demise with the appearance of $\mathrm{OH}$ and coupling amide (see Fig 5)

Chemical modification studies have shown that the cellular components including $\mathrm{N}-\mathrm{H}, \mathrm{CO}$ amide, $\mathrm{SO}_{2}, \mathrm{C}=\mathrm{C}$ and $\mathrm{C}-\mathrm{O}-\mathrm{C}$, (alkynes, nitriles with $\mathrm{CN}$ triple bond), $\mathrm{OH}$, coupling amide and $\mathrm{CH}$ aliphatic. These functional groups are known to act as very active ligands, and therefore tend to bind readily with $U$ and L. REEs ions as a potentials and properties of metal binding.

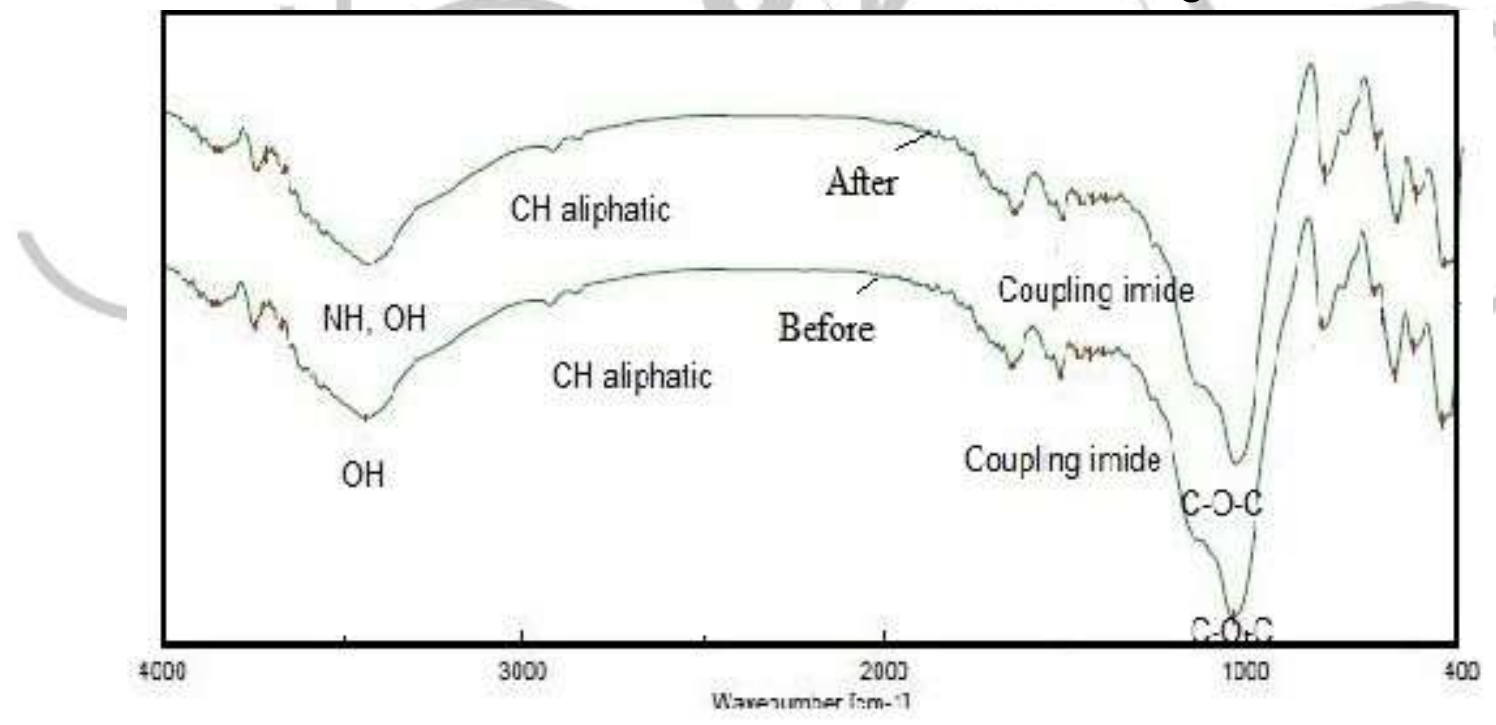

Fig.1: IR analysis data for biosorbent material (S. detofiulum) with the adsorbate No.1. 


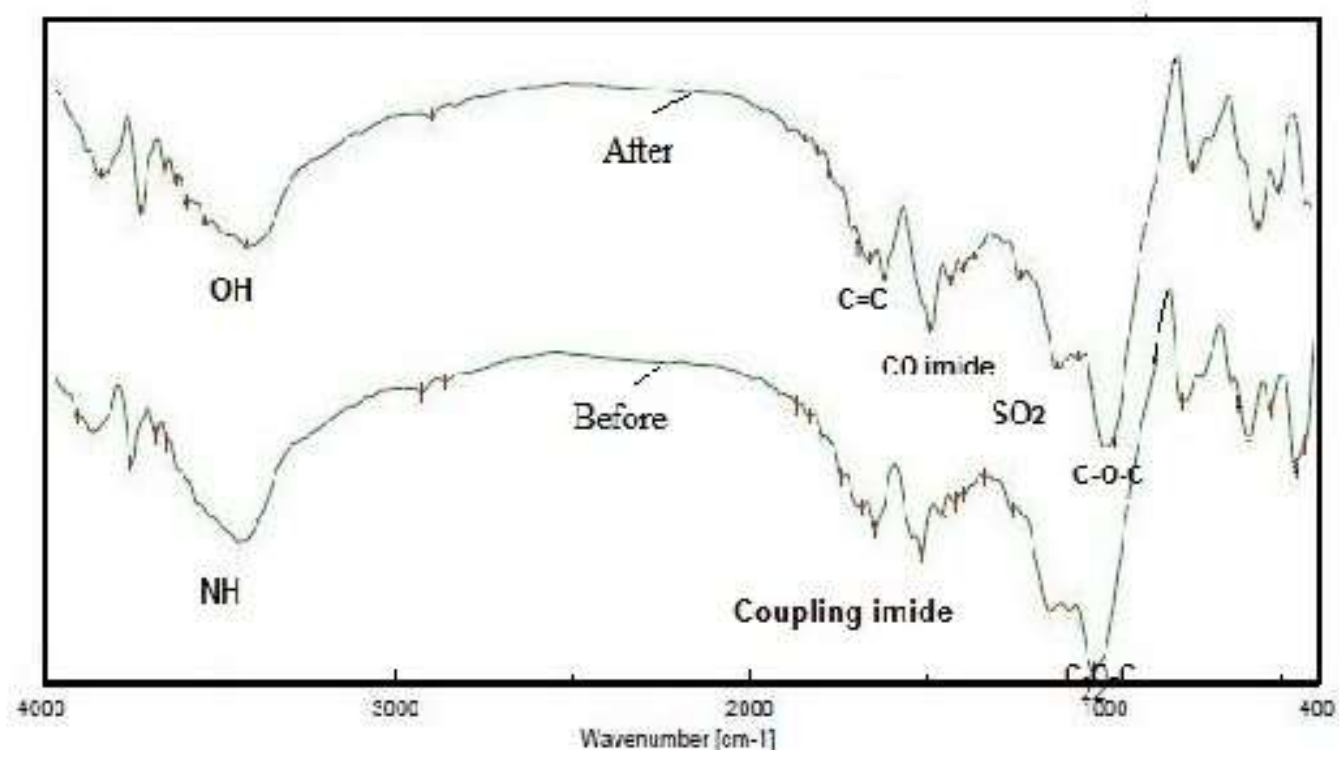

Fig.2: IR analysis data for biosorbent material (S. detofiulum) with the adsorbate No.2.

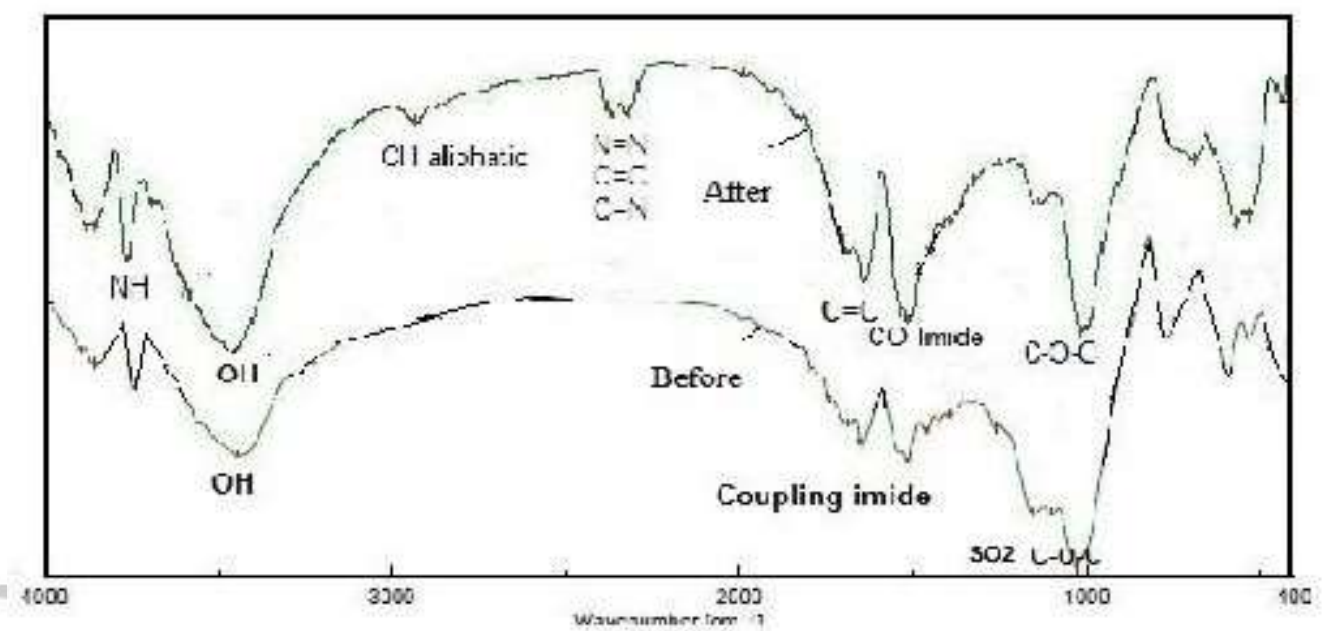

Fig.3: IR analysis data for biosorbent material (S. detofiulum) with the adsorbate No.3.

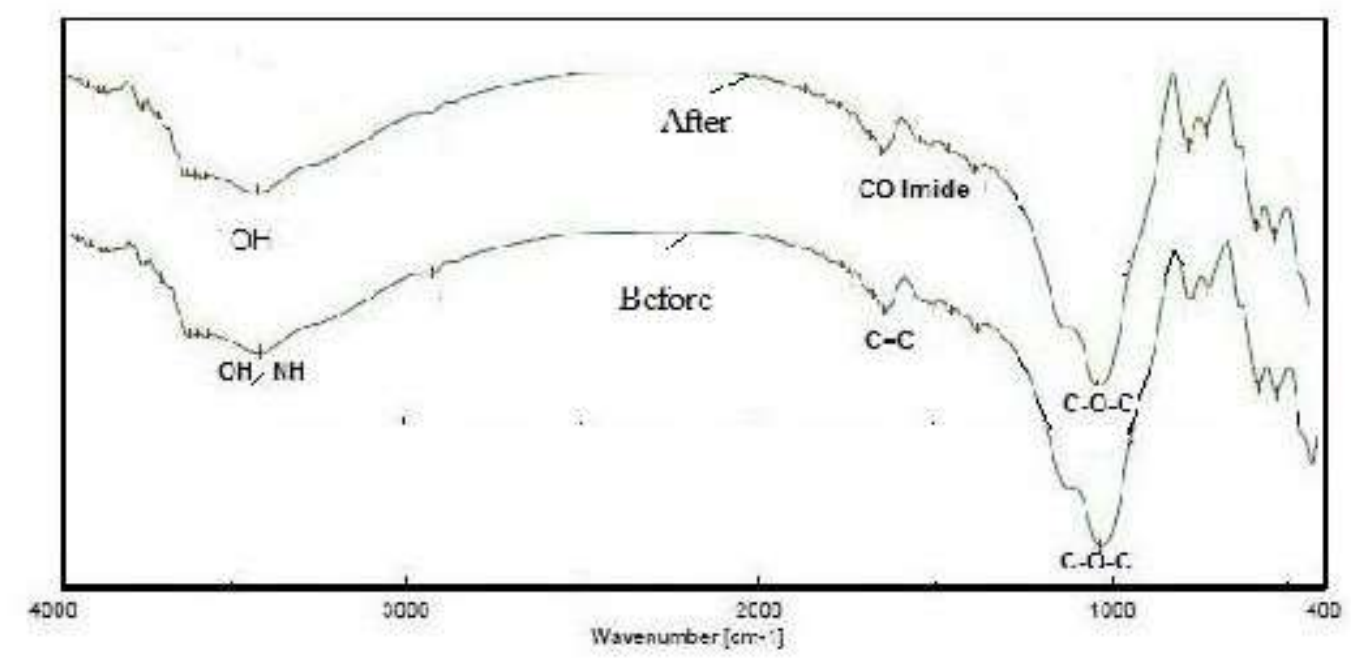

Fig.4: IR analysis data for biosorbent material (S. detofiulum) with the adsorbate No.4. 


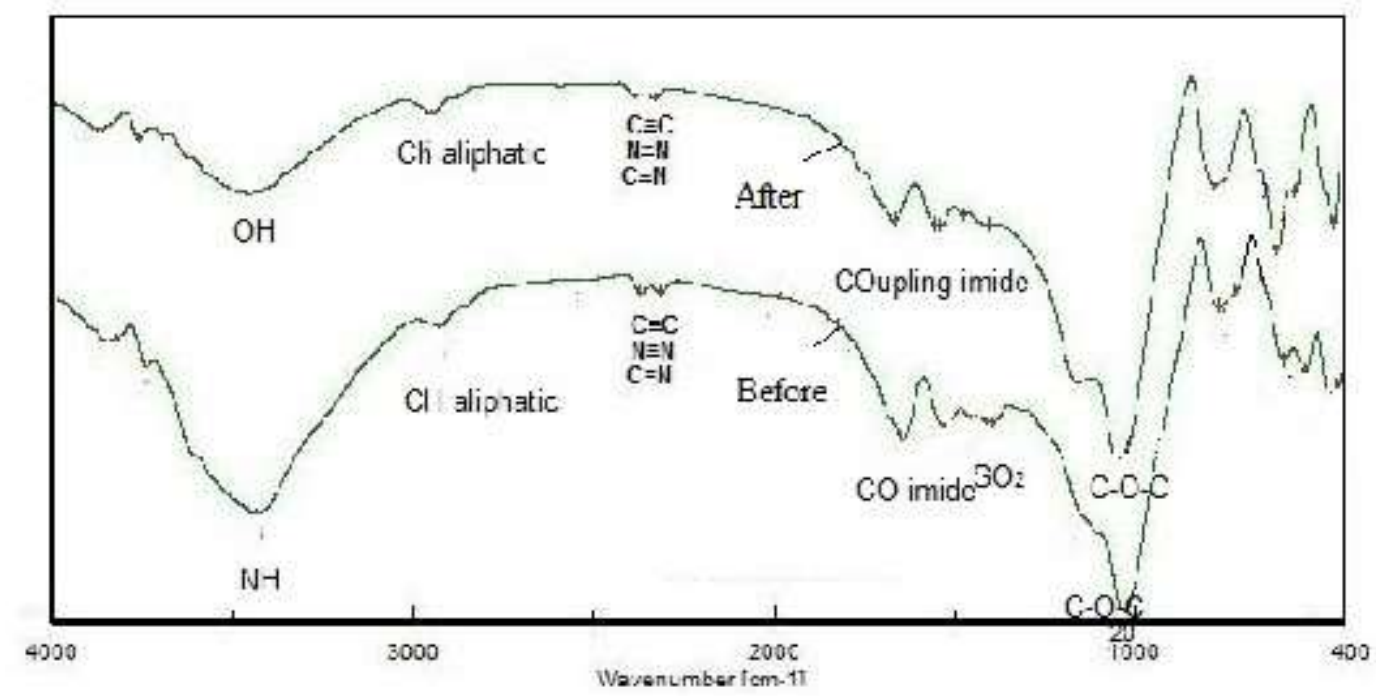

Fig.5: IR analysis data for biosorbent material (S. detofiulum) with the adsorbate No.5.

\subsection{Mechanism of biosorbtion of $U$ and $L$. REEs.}

The adsorbate number.1 has a perfect data for biosorption by $S$. detofiulum to uranium and L. REES so that it is a good example for study biosorption mechanisms.

The mechanism involved in the biosorption process includes complexation, ion exchange and microprecipitation of $U$ and L. REEs. The investigation of the chemical structures of S. detofiulum cells is necessary to understand the mechanism of interaction, also, adsorption depends on either the respective charges on the adsorbing surface and the metallic cation or of the complexation reactions. The S. detofiulum cell consists of the outer wall (macrodeum), middle (codex) and cell center (modula).

\subsection{Complexation}

The Sargassum cell seeks to form an air gaps in the center side of the modula as shown in figure 6 to help it to breath, so it absorbs the oxygen from the surrounding environment. This oxygen is attaches by $U$ and L. REEs (as oxides) because it is tetra- and trivalent $\left(\mathrm{V}^{+4}\right.$ and $V^{+3}$ ) and therefore contains a lot of oxygen as shown in figure (7).

\section{5. lon exchange}

When S. detofiulum cell absorbs oxygen, which is carried by uranium and light rare earth elements, the cell becomes negatively charged and at this time uranium and light rare earth elements become positively charged. so, in this case, there is a convergence between the negatively charged (cell wall) and the positively charged of uranium and L. REEs (see Figs 7 \& 8) indicates the convergence and formation a rim of $U$ and $L$. REES concentrated on the outer layer. Ion exchange reactions depend on the functional groups which are responsible for metal binding (C-O-C, NH, coupling imide, $\mathrm{OH}$ and $\mathrm{CH}$ aliphatic) at the cell surface of $S$. detofiulum, and surface complexation reactions of the sample (see Fig 3). 


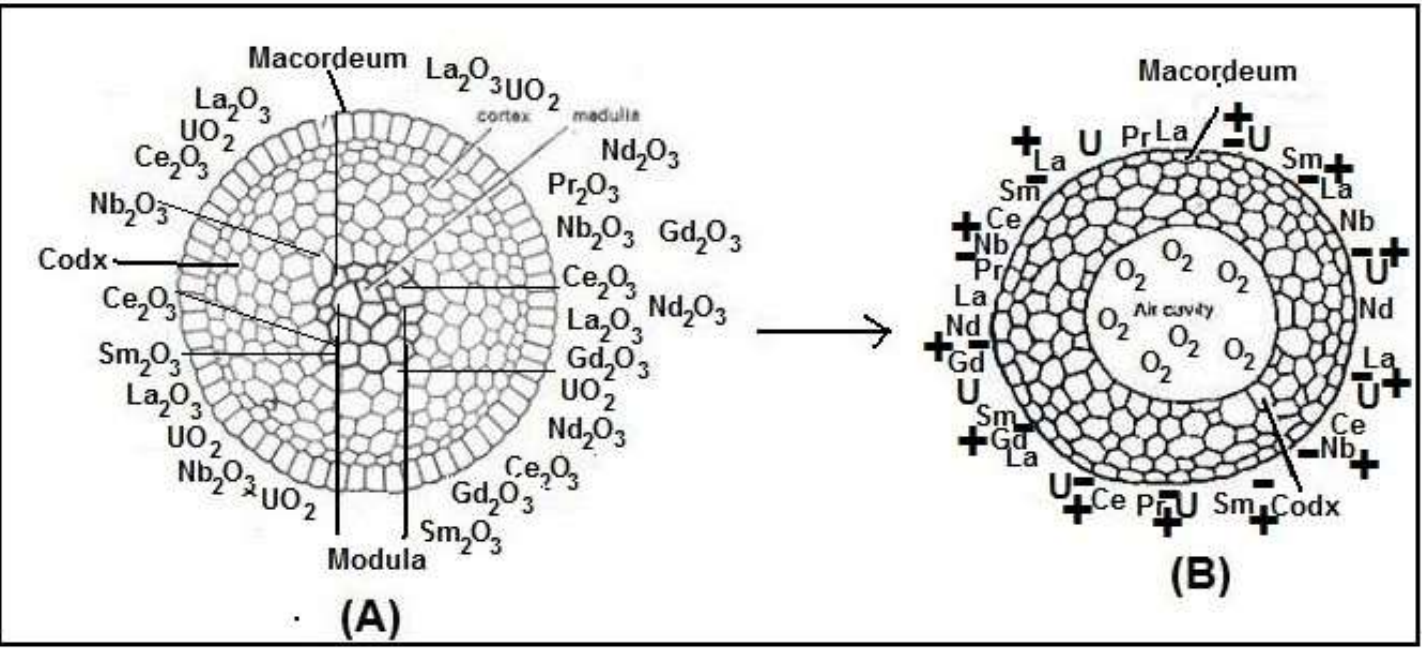

Fig: (7): Mechanism of biosorption Sargassum detofiulum to U and L. REEs.

The transportation of U and L. REEs across S. detofiulum membrane, known as intracellular accumulation, may be mediated by the same mechanism used to convey metabolically important ions such as (U, La, Sm, Ce, Pr and Nb). Cation transport systems may become confused by the presence of $L$. REEs and uranium of the same charge and ionic radius associated with essential ions. This mechanism is not involved with the metabolic activity. Basically, biosorption by living organisms consists of two steps: first, a metabolismindependent binding, where metals are bound to the cell walls; (see Fig 7), as mentioned by Wang and Chen (2009) and second, metabolism-dependent where metal ions are transported across the cell membrane is known as intracellular uptake.

\subsection{Precipitation}

Uranium and L. REEs may be accumulated on the cell walls by sorption-precipitation. Uranium and L. REES removal from the adsorbate is often associated with an active defense system of microorganisms (S. detofiulum). Precipitation, S. detofiulum accumulate U and L. REEs element and collected them in the form of layers like a rim (see Figs 9 \& 10). By identifying this layer using ESEM it indicates the presence of uranium and light REEs (La, Pr, Nd, Sm, Eu and Gd) due the result of ion exchange between the uranium and L. REEs oxides and $S$. detofiulum followed by precipitation (see Figs 11,12 \& 13). For a cellular metabolism-independent the precipitation, it may be a consequence of the chemical interaction between the $U$ and L. REEs and the cell surface. (See Figs 8 \& 14). 

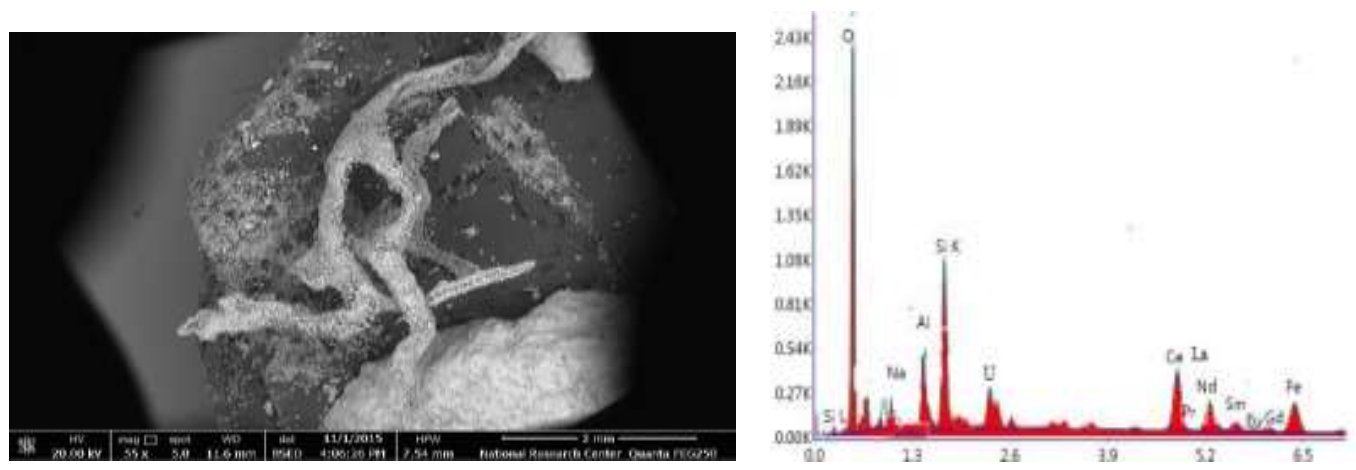

Fig. (8): ESEM Imageand EDX chart of absorption of U and L. REEs on the surface of Sargassum detofiulum
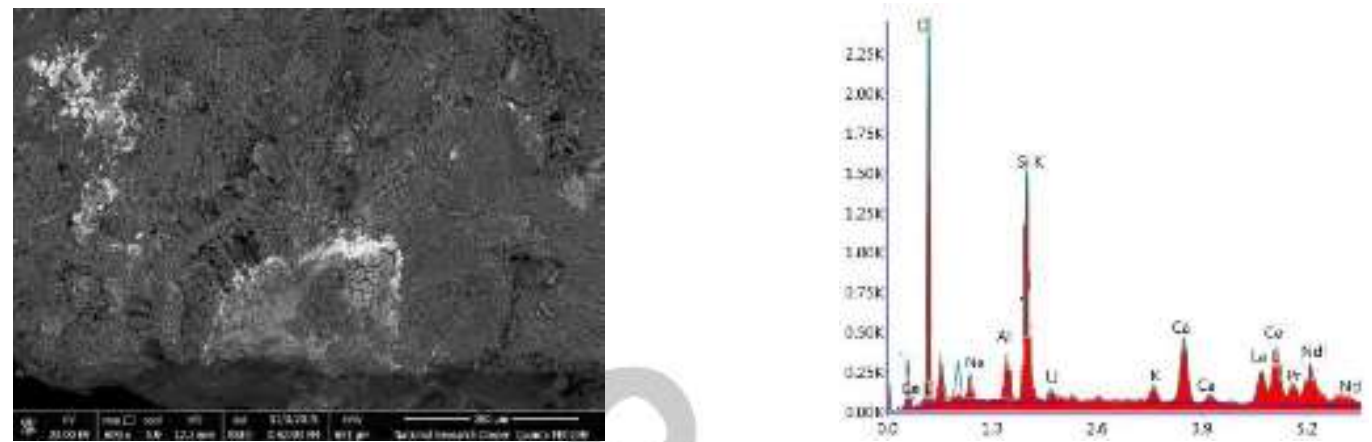

Fig. (9): ESEM Image EDX chart showing absorption of the U and L. REEs on the rim (bright color)
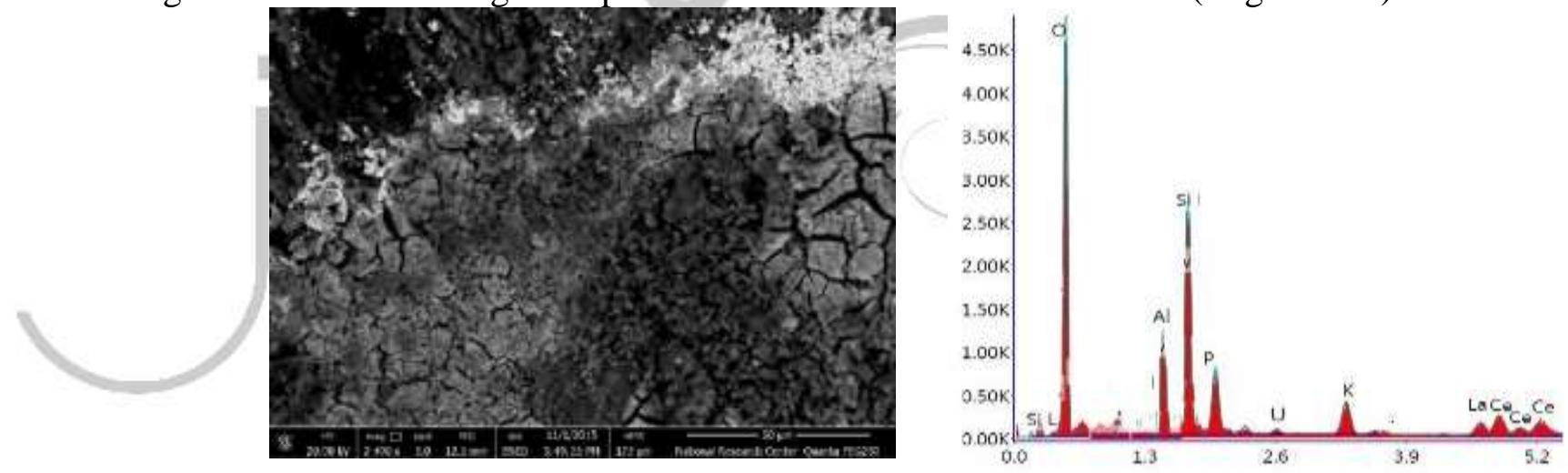

Fig. (10) ESEM Image and EDX chart showing absorption of the U and L. REEs on the rim (bright color high)
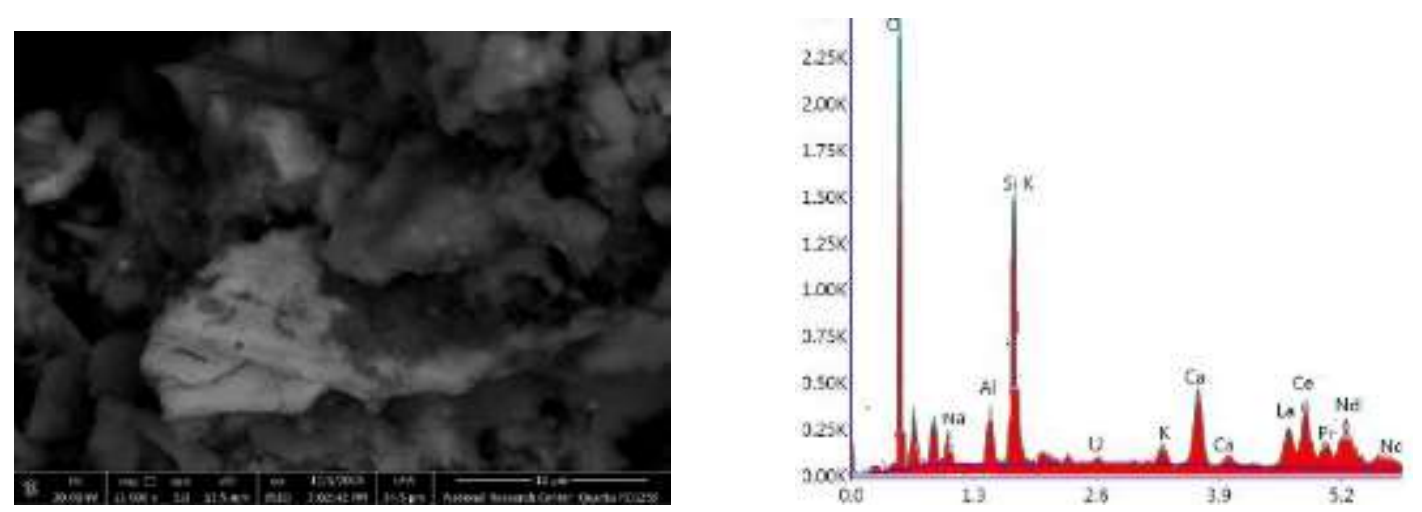

Fig.11.ESEM Image and EDX chart showing the precipitation of U and L. REEs on the surface 

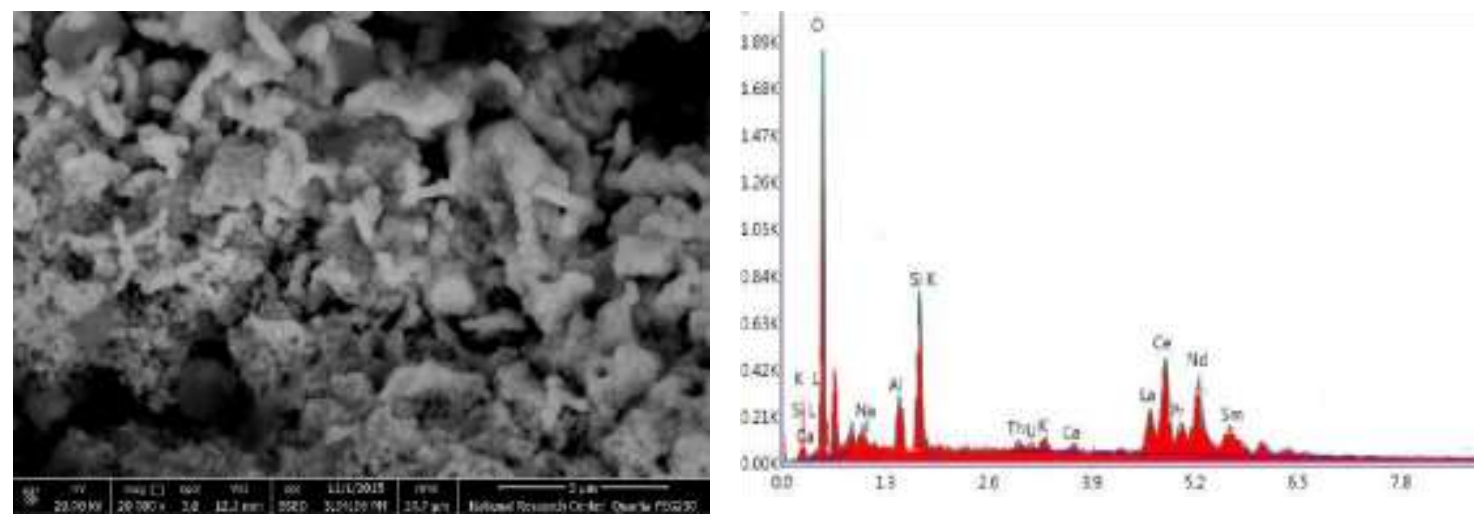

Fig. 12. ESEM Image and EDX chartshowing the absorbed uranium and L. REES
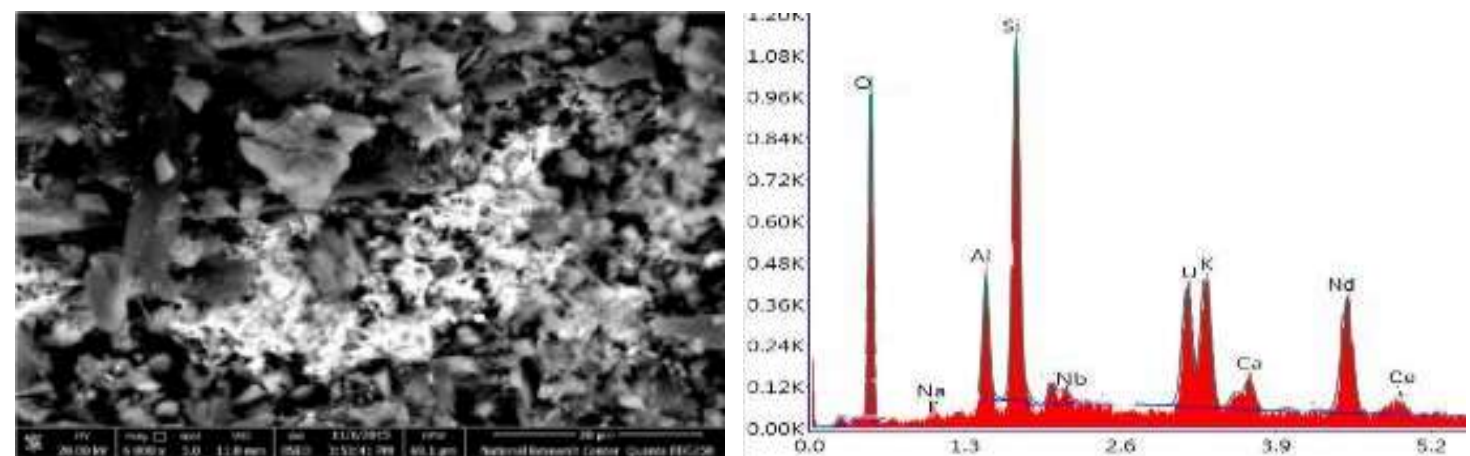

Fig. 13.ESEM Image and EDX chart showing accumulation of $U$ and L. REEson the rim

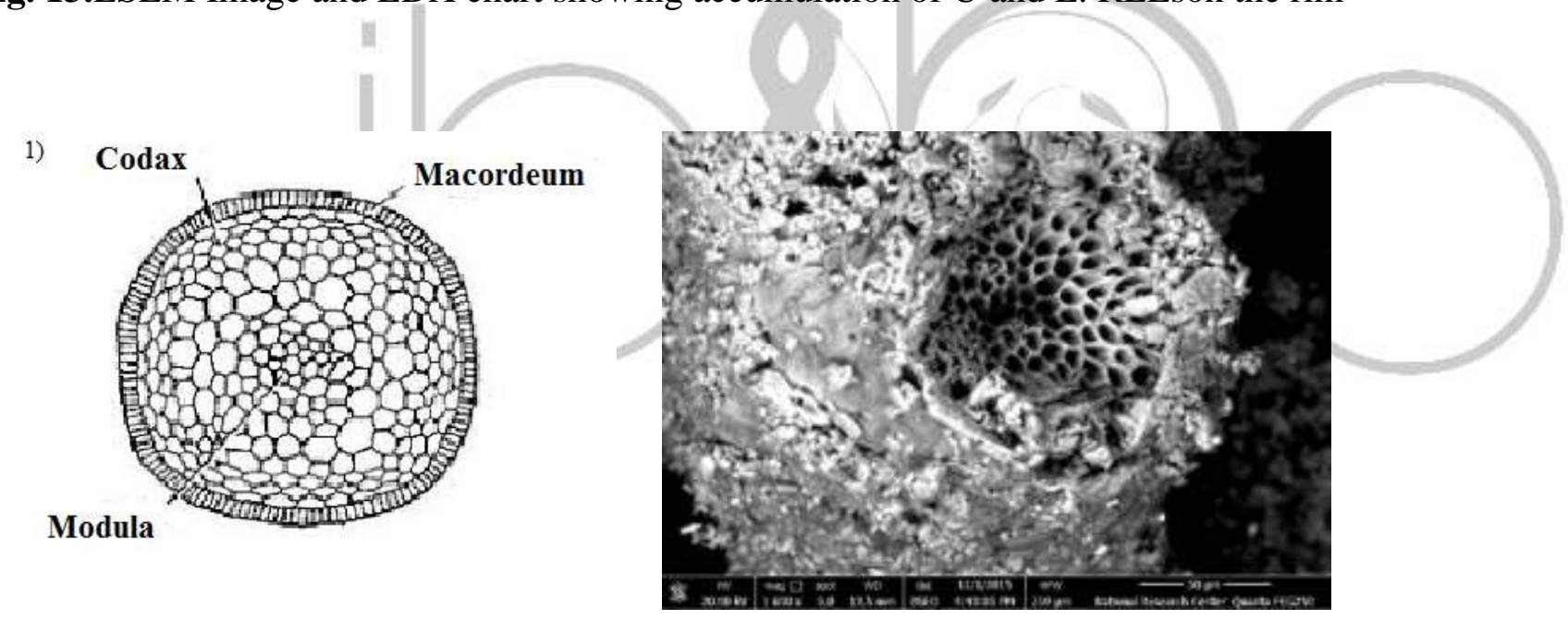

Fig. 6. T.S of Sargassum Cell

Fig.14. ESEM image of Sargassum with the adsorbate (trachyte sills of Nasb El-Atshan)

\section{CONCLUSION}

The mechanisms involved in the biosorption process include complexation, ion exchange and precipitation, there is a convergence between the negatively charged (cell wall) and the positively charged of ( $U$ and L. REEs) this is called complexation then ion exchange happened. Two steps of biosorption happened: first, a metabolism-independent binding, where metals are bound to the cell walls; and second, metabolism-dependent intracellular uptake, where metal ions are transported across the cell membrane and most functional groups, responsible for metal binding to the biomass that found in cell walls.

2021 January Edition | www.jbino.com | Innovative Association 
After that precipitation where $S$. detofiulum accumulate uranium and $\mathrm{L}$. REEs from trachyte sills of Nasb El-Atshan samples and collected them in the form of layers like rims. Therefore, metabolismindependent metal binding to the cell walls and external surfaces is the only mechanism present in this case.

\section{Conflicts of Interest}

The author reports no conflicting interest in any capacity, competing or financial.

\section{Acknowledgment}

The authors are grateful to NMA, Egypt to the facilities in laboratory services for this research work.

\section{REFERENCES}

Abou Zeid, A. A., Hassanein, W. A., Salama, H. M. \& Fahd, G. A. A. (2009). Biosorption of some heavy metal ions using bacterial species isolated from agriculture waste water drains in Egypt. Journal of Applied Sciences Research 5,372-383.

Azzoni, A., La Barbera, G., and Zaninetti, A., (1995). Analysis and prediction of rockfalls 110 using a mathematical model. International Journal of Rock Mechanics and Mining 111 Sciences, 32, 709-724.

Diniz V, Webera M E, Volesky B, Naja G. (2008). Column biosorption of lanthanum and europium by Sargassum. Water Research 42, 363-371.
Gadd GM (2001). Fungi in Bioremediation. Cambridge University Press, Cambridge, UK.

Hasan H A, Abdullah SRS, Kofli NT, Kamaruddin SK. (2010). Biosorption of manganese in drinking water by isolated bacteria. Journal of Applied Sciences 10, 2653-2657.

Hanan . H .Omer . (2008). Biosorption of Copper, Nickel and Manganese using Non-Living Biomass of Marine Algae, Ulva Lactuca. Pakistan journal of Biological science 11 (7):964-973.

Kato K, Maruta F, Kon N , Tonouchi S. (2003). Distributions and behaviors of C137s and stable Cs in seawater and marine algae on the coast of Niigata Prefecture, Annual Report, Niigata Prefectural Institute of Environmental Radiation Monitoring, Niigata, Japan.

Kulbat E, Olan'czuk-Neyman K, Quant B, Geneja M. , Haustein E. (2003). Heavy metals removal in the mechanicalbioloical wastewater treatment plant 'Wschód' in Gdan'sk, Polish. Journal of Environmental Studies .12, 635-641.

Senthilkumaar, S., Bharathi, S., Nithyanandhi, D. \& Subburam, V. (2000). Biosorption of toxic heavy metals from aqueous solutions. Bioresource Technology 75, 163-165.

Wang J and Chen C. (2009). Biosorbents for heavy metals removal and their future. Biotechnology Advances. 27, 195226. 
Zouboulis A I, Rousou E G, Matis KA.

Hancock I C. (1999). Removal of toxic metals from aqueous mixtures. Partl. Biosorption. Journal of Chemical Technology and Biotechnology 74, 429436. 